\title{
Survey on the introduction of complementary foods to infants within the first six months and associated factors in rural communities of Jimma Arjo
}

\author{
Dessalegn Tamiru', Dayan Aragu', Tefera Belachew ${ }^{2}$ \\ ${ }^{1}$ Public Health Department, Arbaminch University, Arba Minch, Ethiopia \\ ${ }^{2}$ Departmentof Population and Family Health, Jimma University, Jimma, Ethiopia
}

Email address:

dassutami@yahoo.com (D. Tamiru),daueunited@yahoo.com (D. Aragu), Tefera_Belachew@yahoo.com (T. Belachew)

\section{To cite this article:}

Dessalegn Tamiru, Dayan Aragu, Tefera Belachew. Survey on the Introduction of Complementary Foods to Infants within the First Six Months and Associated Factors in Rural Communities of Jimma Arjo, International Journal of Nutrition and Food Sciences. Vol. 2, No. 2, 2013, pp. 77-84. doi: 10.11648/j.ijnfs.20130202.18

\begin{abstract}
Background: Although breastfeeding is one of the components of Primary Health Care in Ethiopia, a wide range of harmful infant feeding practices are documented even after the implementation of infant and young child feeding guidelines. However, no studies were documented about complementary feeding patterns and factors associated with early introduction of complementary feeding in the study area. Methods and Materials: Community based cross-sectional study was carried out in JimmaArjoWoreda from December to January 2009. Quantitative data were collected from a sample of 382 respondents supplemented by qualitative data generated using in-depth interviews of 15 key informants.Data were analyzed using SPSS version 16.0. Binary logistic regressions were used to measure the strength of association between independent and dependent variables using odds ratios and $95 \%$ of confidence intervals. Finally, multivariate logistic regression analysis was done to identify the predictors of early introduction of complementary food. Results: About $42.9 \%$ of mothers initiated complementary feeding before 6 months. The majority of mothers early initiated complementary feeding since they believed that breast milk was insufficient and influences from social beliefs. Findings from this study showed that young maternal age, child age below 1 month, child age 1-2 months, breastfeeding initiation within the first hour of child birth, having information about exclusive breastfeeding and maternal attitude about the dietary importance of breast milk for their children were negatively associated with early introduction of complementary food. However, lack of sufficient time with their children was one of predisposing factor for early introduction of the additional food before 6 months. Conclusions: Findings from this study showed that $42.9 \%$ of mothers introduced complementary food before 6 months. As this can cause malnutrition and exposure to different types of infections, the contributing factors to early introduction of complementary food should be taken into account while designing intervention strategies. In addition promotion of strong community based networks using Health Extension Workers and local community's resource people as key actors is important to tackle this problem.
\end{abstract}

Keywords: Introduction, Complementary, JimmaArjo, Breastfeeding

\section{Background}

In the world $60 \%$ of the infant and young child deaths occur due to malnutrition where two-thirds of these deaths attributed to sub-optimal child feeding practices and infectious disease [1]. The impacts of inappropriate infant feeding practice are great in developing countries where access to basic needs and health services are not adequately available $[2,3]$.

As WHO definition optimal infant feeding practices is initiation of breastfeeding within 1 hour of birth; exclusive breastfeeding for first 6 months of life; introduction of complementary food from locally available food and hygienically prepared around 6 months; increased breastfeeding during illness and recovery and also continued breastfeeding for up to 2 years of age $[1,4]$.

In developing countries early and abrupt cessation of breastfeeding followed by an introduction of dirty and unsound artificial feeding of infants with very dilute milk products is common where children are more vulnerable to infection with different pathogens since their body nutrient store is not well developed $[2,4,5]$. Large numbers of 
mothers do not appropriately breastfeed during the first 6 months of life. With the decline in breastfeeding, there is a shift to bottle-feeding, which could be hazardous [5, 9].

In some societies' culture, plain water, butter and others food are given for newborn infants [3, 21, 28]. It is considered as preventive measures against disease and symbol of welcoming the baby. Consequently butter, sugar and water are fed to the baby while the colostrum is discarded as unclean; breastfeeding is started when the breast milk becomes clearer after a few days $[13,14]$. In developed countries perception that infants at work may hinder mothers' job performance; lack of privacy for breastfeeding and insurance regulations and others are some barriers to breastfeeding and factors of early introduction of complementary food [7, 15].

Early introduction of liquids and solid foods at too early age increases the risk of diarrheal disease and important causes of infant and young children morbidity and mortality in Africa [6, 7]. In addition infant and child feeding practices are major determinants of the risks of malnutrition which has been playing great role for more than half of infant and young children deaths in a year [4, 8].Those malnourished children who survive are more frequently sick and suffer the lifelong consequences of impaired development $[4,7,8]$.

Health workers support breastfeeding, because breast milk is the only appropriate food for new born infants and the most nutritious food for babies [4, 3, 9]. There is no artificial feeding formula which can replace breast milk to provide basic nutrients and protection against diseases during the first 6 months of life [1,9].

Infants' right to adequate food needs to be improved, as only about one-third of the world's infants begin breastfeeding within one hour and are exclusively breastfed for the first six months $[1,4]$. The reason most frequently given forthe early introduction of solids is the majority of mothersthought that breast milk alone cannot satisfy a child $[4,10,13,16]$. Thus there is a need for a clear-cut program to provide a basic service and support for pregnant and lactating women $[4,11]$. In the world as a whole large number of women do not appropriately breastfeed or do so only for a short period of time. On the bases of experience in traditional societies, very few mothers are unable to breastfeed for physiological reasons $[1,2,9]$.

Introducing solid foods into an infant's diet is recommended at about six months because at that age breast milk is no longer adequate in meeting a child's nutritional needs to promote optimal growth $[1,2,6]$. At about six months of age, breast milk is not sufficient to meet energy, protein and micronutrient requirements of most infants and young children $[1,2,6,17]$. So, locally available foods that are rich in both macronutrient and micronutrient, hygienically prepared and suitable to eat need to be provided [1, 12]. During the transitional period when complementary foods are being introduced, on-demand and frequent breastfeeding should continue to ensure that infants receive all the benefits of breastfeeding $[1,6]$.
Families in difficult situations require special attention and practical support to be able to feed their children appropriately. In such cases the probabilities of breastfeeding decreases and there can be an increasing of artificial feeding and inappropriate complementary feeding [3, 4]. Mothers and babies should stay together and provided the support they need to maintain the appropriate child feeding option under the difficult circumstances $[1,4,15]$.

Breastfeeding is common practice in Ethiopia. However, large proportions of women do not practice appropriate breastfeeding and complementary feeding behavior for their children [17]. According to 2012 the Ethiopian Demographic Health Survey report, 27\% of mothers provide water, butter, and various types of food to feed their children, thereby reducing the percentage of exclusively breastfeed and increasing the percentage of receiving complementary food at very young age [18]. Nationally, 50.6\% of newborns were put on breast within 1 hour of birth and about $80 \%$ of infants 2 months old are exclusive breastfed.However, this proportion rapidly drops to $38 \%$ at the age of 6 months and complementary feeding starts too early in about $14 \%$ of infants [3, 18].

Although breastfeeding is one of the components of Primary Health Care in Ethiopia, a wide range of harmful infant feeding practices are documented even after the implementation of infant and young child feeding guide line. However, no studies were documented about complementary feeding patterns and factors associated with early introduction of complementary feeding in the study area.Therefore this study aimed to assess introduction of complementary foods to infants within the first six months and associated factors in rural communities of JimmaArjoWoreda.

\section{Methods and Materials}

\subsection{Study Setting and Sample}

This cross-sectional community basedstudy was carried out at JimmaArjoWoreda from December to January 2009. JimmaArjoworedais located at $327 \mathrm{~km}$ from Addis Ababa to the southwest of Ethiopia. Total population of JimmaArjoWoreda is estimated to be 127,750 in which 89,375 were rural population [29].Most of the people depend on traditional subsistence agriculture for living. The main crops produced in the area are maize, sorghum and coffee. From 20 rural kebeles, 8 kebeles were selected using probability proportional to size allocation methods. Then infant-mother pairs were randomly selected from the sampling frame. Finally 384 mothers who had children less than 6 months were selected using simple random sampling technique. Fifteen key informants were purposively selected based on their role in the community for in-depth interview to capture their first-hand knowledge about child feeding practices. The sample size was calculated using a formula for estimation of single proportion asfollows: 


$$
n=\frac{(Z a / 2)^{2} p(1-p)}{d^{2}}
$$

Where

$\mathrm{Z}=$ Standard normal variable at $95 \%$ confidence level (1.96)

$\mathrm{p}=$ Estimated proportion of early introduction of complementaryfood, $50 \%$

$\mathrm{d}=0.05$ (5\% margin of error) $[30]$

\subsection{Data Collection}

Pre-tested structured and non-structured questionnaires were used to collect data from 382 mothers supplemented with qualitative data from 15 mothers. In-depth interview was used to generate descriptions of women's infant feeding practices. This allowed each participant to contribute their own knowledge of breastfeeding within broadly defined research themes that are going to be explored. All interviews were conducted by the data collectors in the participant's home.The interviewer assisted each key informant to understand informational contents of questions during interview sessions. Audio tape recorders were used with the consent of each individual and then transcribed as verbatim. Both quantitative and qualitative questionnaires were prepared in English and translated to Afan Oromo. Then, they were retranslated to English language by a person who can speak both languages. Every completed questionnaire was handled by supervisors after data collection and finally the principal investigator monitored the overall quality of the data collection.

\subsection{Data Processing and Analysis}

Data were entered and analyzed using SPSS (SPSS Inc. version 16.0, Chicago, Illinois). The data were checked for missing values and outliers.Bivariate and multivariate analyses were used to examine the relationship betweenindependent and dependent variable using odds ratios and 95\% of confidence intervals. Bivariate analyses were carried out to identify candidate variables for the multivariable model. Multivariate logistic regression analyses were used to identify significant predictors of the outcome variable.

Qualitative data were analyzed based on the responsesfrom the respondents. The members sat in a group to discuss the findings and compare information from different sources. They tried to find out if the various people got the same impression and if there were differences in idea.Qualitative datawere analyzed by system of open coding which involves sorting the data into analytical categories by breaking down, examining, comparing and categorizing data.Finally the categories of data were compared and contrasted to generate themes from the analysis. On completion of the research qualitative findings were presented in triangulation with the quantitative one.

\subsection{Ethical Consideration}

The study was carried out after getting ethical clearance and official permission from Hawassa University and JimmaArjoWoreda administration. Prior to the first intervieweach respondent was informed about objective of the study and privacy during the interview. Then informed verbal consent was obtained from each study participant.

\section{Results}

Out of 384 study participants intended to be included, complete response was obtained from 382(99.48\%) of respondents. The mean $( \pm \mathrm{SD})$ age of the mothers was 25.9 years $( \pm 5.15)$. The majority of study participants $(71.7 \%)$ did not attend any types of formal education (Table 1).

Table 1. Socio-demographic Characteristics of Study Participants in JimmaArjoWoreda, 2009.

\begin{tabular}{|c|c|c|}
\hline VariableFrequency (n) & Percent (\%) & \\
\hline \multicolumn{3}{|l|}{ Maternal age } \\
\hline$\leq 20$ & 43 & 11.3 \\
\hline $21-25$ & 191 & 50 \\
\hline $26-30$ & 98 & 25.6 \\
\hline$\geq 31$ & 50 & 13.1 \\
\hline \multicolumn{3}{|l|}{ Number of under 5 children } \\
\hline 1 & 114 & 29.8 \\
\hline 2 & 210 & 55 \\
\hline$\geq 3$ & 58 & 15.2 \\
\hline \multicolumn{3}{|l|}{ Maternal education } \\
\hline Illiterate & 274 & 71.7 \\
\hline Reading and writing & 45 & 11.8 \\
\hline Primary school and above & 63 & 15.5 \\
\hline \multicolumn{3}{|l|}{ Maternal occupation } \\
\hline Housewife only & 136 & 35.6 \\
\hline Farmer & 227 & 59.4 \\
\hline Government and private employer & 16 & 4.2 \\
\hline Others & 3 & 0.8 \\
\hline \multicolumn{3}{|l|}{ Utilization of family planning } \\
\hline Yes & 244 & 63.87 \\
\hline No & 138 & 36.13 \\
\hline \multicolumn{3}{|l|}{ Total number of birth } \\
\hline $1-2$ & 151 & 39.6 \\
\hline $3-4$ & 135 & 35.3 \\
\hline$>4$ & 96 & 25.1 \\
\hline \multicolumn{3}{|l|}{ Infants age } \\
\hline$\geq 2$ & 122 & 32 \\
\hline $3-4$ & 89 & 23.3 \\
\hline $5-6$ & 171 & 44.7 \\
\hline \multicolumn{3}{|l|}{ Birth order } \\
\hline First & 78 & 20.4 \\
\hline Second & 86 & 22.5 \\
\hline Third and above & 218 & 57.1 \\
\hline \multicolumn{3}{|l|}{ Baby's Gender } \\
\hline Male & 193 & 50.5 \\
\hline Female & 189 & 49.5 \\
\hline \multicolumn{3}{|l|}{ Place of delivery } \\
\hline Home & 354 & 92.7 \\
\hline Health center and Hospital & 28 & 7.3 \\
\hline \multicolumn{3}{|l|}{ Farm land owners } \\
\hline No & 27 & 7.06 \\
\hline Yes & 355 & 92.94 \\
\hline
\end{tabular}


Findings form this study indicated that small proportion of mothers $(1.6 \%)$ believed breastfeeding takes too much time and $(3.1 \%)$ reported their breast was too small. Some women $(15.7 \%)$ believed that additional food protects against evil eyes and stomachache. One hundred-sixty mothers $(41.88 \%)$ believed that complementary food provides more nutrients than breast milk.

In-depth interview with mothers similarly showed that some mothers had no information about time of initiation of complementary food. Twenty years old mother said:

"...this is what my mother and others did for their children; breast milk alone maybe not sufficient for normal growth and development of child....."

Majority of mothers (47.4\%) mothers had information about the adequacy of breast milk for six months. Qualitative findings also showed that mothers who had basic knowledge about dietary importance of breast milk do not early introduced complementary food. Thirty two years Traditional Birth Attendant said:

"...breast milk is sufficient for 6 months and currently what majority of mothers is encouraged to do by health workers..."

Table 2.Maternal Knowledge and Attitude about Complementary Food and Breast Milk in JimmaArjoWoreda, 2009.

\begin{tabular}{lll}
\hline Variable & Number(n) Percent (\%) \\
\hline Breastfeeding takes too much time & 6 & 1.6 \\
My breast is too small & 12 & 3.1 \\
Fluid is used to clean stomach & 19 & 5 \\
Bottle feeding is good & 10 & 2.6 \\
Complementary food protect from evil eye & 60 & 15.7 \\
Complementary food is good for growth & 160 & 41.88 \\
It is our culture & & 5.2 \\
Breast milk is sufficient to 6 months & 181 & 47.4 \\
\hline
\end{tabular}

About $81(46.29 \%)$ and 53(13.9\%) of mothers provided cow's milk and yogurt before six months for infants respectively. Sixty-four (36.57\%) mother gave formula milk. With the mixture fenugreek, 64(16.8) mothers gave tenaaddam (rue) as they considered it as preventive medicine against stomachache and others disease.

Similarly, the in-depth interview with mothers indicated that some mothers traditionally gave tena-addam (rue), butter, water and fenugreek since they considered these as a preventive medicine against disease. Twenty-two years breastfeeding mothers said:

"... butter, tena-addam (rue), and fenugreek were given as treatment for stomachache and common cold for children..."
Table 3. Types of Complementary Food Given Before 6 Months for Infants in JimmaArjoWoreda, 2009.

\begin{tabular}{lll}
\hline Variable & Number & Frequency \\
\hline Cow's milk & 81 & 46.29 \\
Butter & 16 & 9.14 \\
Sugar solution & 4 & 2.29 \\
Formula milk & 64 & 36.57 \\
TenaAddam & 64 & 16.8 \\
Yugort & 53 & 13.9 \\
Injera & 7 & 4.0 \\
Others & 3 & 1.71 \\
\hline
\end{tabular}

The results showed that about $42.9 \%$ of mothers early introduced complementary food before 6 months. Maternal age, child age and keeping livestock were found significantly associated with early introduction of complementary feeding (Table 4). Young mothers (15-20 years) less likely early introduced complementary food before 6 months compared to mothers whose their age above 20 years $(\mathrm{AOR}=0.36[95 \% \mathrm{CI}: 0.14,0.97])$.

Early introduction of complementary food before 6 months found negatively associated with infants' age. Mothers who had below 1 month infants were less likely early introduced complementary food compared to mothers who had 5-6 months (AOR=0.20[95\% CI: 0.11, 0.34]). Similarly, mothers who had 1-2 months infants were less likely early introduced complementary food compared to mothers who had 5-6 months (AOR $=0.34[95 \% \mathrm{CI}$ : 0.19 , 0.59]).

Keeping livestock is positively associated with early introduction of complementary food. Mothers who gave some of their time to keep livestock were more likely early introduced complementary food before 6 months compared to their counterparts $(\mathrm{AOR}=1.60$ [95\% CI: 1.92, 2.80]). Similarly in-depth interview with mothers showed field activity is the major constraint of optimal infant feeding practices. Twenty-six years old breastfeeding mother said:

"... I have no sufficient time to breastfeed the whole day due to field activities; so when I left home I gave cow's milk to the elders"

The result of multivariable regression revealed that mothers' preference for her child, exclusive breastfeeding information, knowledge about the duration of exclusive breastfeeding and mothers' attitude about additional food were significantly associated with early introduction of complementary food.

Mothers who initiated breastfeeding within the first hour of delivery less likely early introduced complementary food before 6 months than who started after one hour of delivery $(\mathrm{AOR}=0.52[95 \% \mathrm{CI}=0.32,0.84])$. 
Table 4. Factors associated with early introduction of complementary food before 6 months inJimmaArjoWoreda, 2009.

\begin{tabular}{|c|c|c|c|c|}
\hline \multirow{2}{*}{ Variable } & \multicolumn{4}{|c|}{$\begin{array}{l}\text { Early Introduction of Complementary } \\
\text { Food before } 6 \text { months }\end{array}$} \\
\hline & Yes & No & $\operatorname{COR}(95 \% \mathrm{CI})$ & $\begin{array}{l}\text { AOR }(95 \% \\
\text { CI) }\end{array}$ \\
\hline Maternal age (in years) & & & & $\begin{array}{l}0.36(0.14 \\
0.97)^{*}\end{array}$ \\
\hline $15-20$ & 11 & 32 & $0.47(0.19,1.11)$ & $0.73(0.36$ \\
\hline $21-25$ & 80 & 111 & $0.99(0.51,1.80)$ & $1.46)$ \\
\hline $26-30$ & 52 & 46 & $1.56(0.76,3.01)$ & $\begin{array}{l}1.32(0.62 \\
2.79)\end{array}$ \\
\hline$>31$ & 21 & 29 & 1 & 1 \\
\hline \multicolumn{5}{|l|}{ ANC follow up } \\
\hline Yes & 83 & 109 & $1.03(0.68,1.54)$ & _- \\
\hline No & 81 & 109 & 1 & \\
\hline \multicolumn{5}{|l|}{ Sex of a child } \\
\hline Female & 80 & 113 & $0.89(0.59,1.33)$ & \\
\hline Male & 84 & 105 & 1 & - \\
\hline \multicolumn{5}{|l|}{ Type of delivery } \\
\hline Caesarian & 5 & 3 & $2.25(0.53,9.57)$ & \\
\hline Natural & 159 & 215 & 1 & - \\
\hline Child age (in months) & & & & \\
\hline Below 1 & 29 & 93 & $\begin{array}{l}0.20(0.12 \\
0.33)^{* * *}\end{array}$ & $\begin{array}{l}0.20(0.11 \\
0.34) * * *\end{array}$ \\
\hline $1-2$ & 30 & 58 & $\begin{array}{l}0.33(0.19 \\
0.56)^{* * *}\end{array}$ & $\begin{array}{l}0.34(0.19 \\
0.59)^{* * *}\end{array}$ \\
\hline $3-4$ & 1 & 1 & $0.64(0.04,10.32)$ & $\begin{array}{l}0.41(0.02 \\
7.73)\end{array}$ \\
\hline & & & 1 & 1 \\
\hline \multicolumn{5}{|l|}{ Maternal education } \\
\hline No education & 115 & 159 & $0.90(0.52,1.57)$ & \\
\hline Reading and writing & 21 & 24 & $1.09(0.51,2.36)$ & - \\
\hline Elementary and above & 28 & 35 & 1 & \\
\hline \multicolumn{5}{|l|}{ Delivery assistant } \\
\hline TBA2 & 134 & 179 & $0.96(0.70,2.76)$ & - \\
\hline
\end{tabular}

\begin{tabular}{|c|c|c|c|c|}
\hline Health workers & 23 & 30 & $0.98(0.86,6.08)$ & \\
\hline and HEW1 & 7 & 9 & 1 & \\
\hline \multicolumn{5}{|l|}{ Relatives } \\
\hline \multicolumn{5}{|l|}{ Home activity } \\
\hline Mothers & 134 & 168 & $1.33(0.80,2.21)$ & \\
\hline Others & 30 & 50 & 1 & - \\
\hline \multicolumn{5}{|l|}{ Having radio } \\
\hline Yes & 81 & 100 & $1.15(0.58,1.30)$ & \\
\hline No & 83 & 118 & 1 & - \\
\hline \multicolumn{5}{|c|}{ Keeping live stock } \\
\hline Yes & 41 & 36 & $1.68(1.02,2.79)^{*}$ & $\begin{array}{l}1.60(1.92 \\
2.80)^{*}\end{array}$ \\
\hline No & 123 & 182 & 1 & 1 \\
\hline
\end{tabular}

***Significant at 0.001, *significant at $0.05,{ }^{1}$ Health Extension workers ${ }^{2}$ Traditional Birth Attendants.

Mothers who had information about exclusive breastfeeding to six months were less likely early introduced additional food compared to who had no information about exclusive breastfeeding (AOR $=0.43[0.06,0.99])$. Similarly, the qualitative findings showed that maternal exposure to breastfeeding education had greater role in the enhancement of optimal child feeding practices. Twenty three years old breastfeeding mother said:

"...I gave cow's milk before 6 months for my first child, but for my current child I didn't give any things except breast milk because now I know the impact of early introduction of complementary feeding on child growth and development."

Maternal food preference for their children had significant contribution to the initiation of complementary feeding. Mothers who preferred breast milk for their children were less likely gave additional food $(\mathrm{AOR}=0.15(95 \% \mathrm{CI}=0.05$, $0.45]$ ) before six months compared to who preferred other forms of food like cow's milk and others.

Mothers who thought that complementary food is good for normal growth child were more likely to introduce complementary food than who had no such perception $(\mathrm{AOR}=4.24[95 \% \mathrm{CI}=2.33,7.71])$. 
Table 5. Association of breastfeeding practicesand maternal knowledge with introduction of complementary food before six months in JimmaArjoWoreda, 2009.

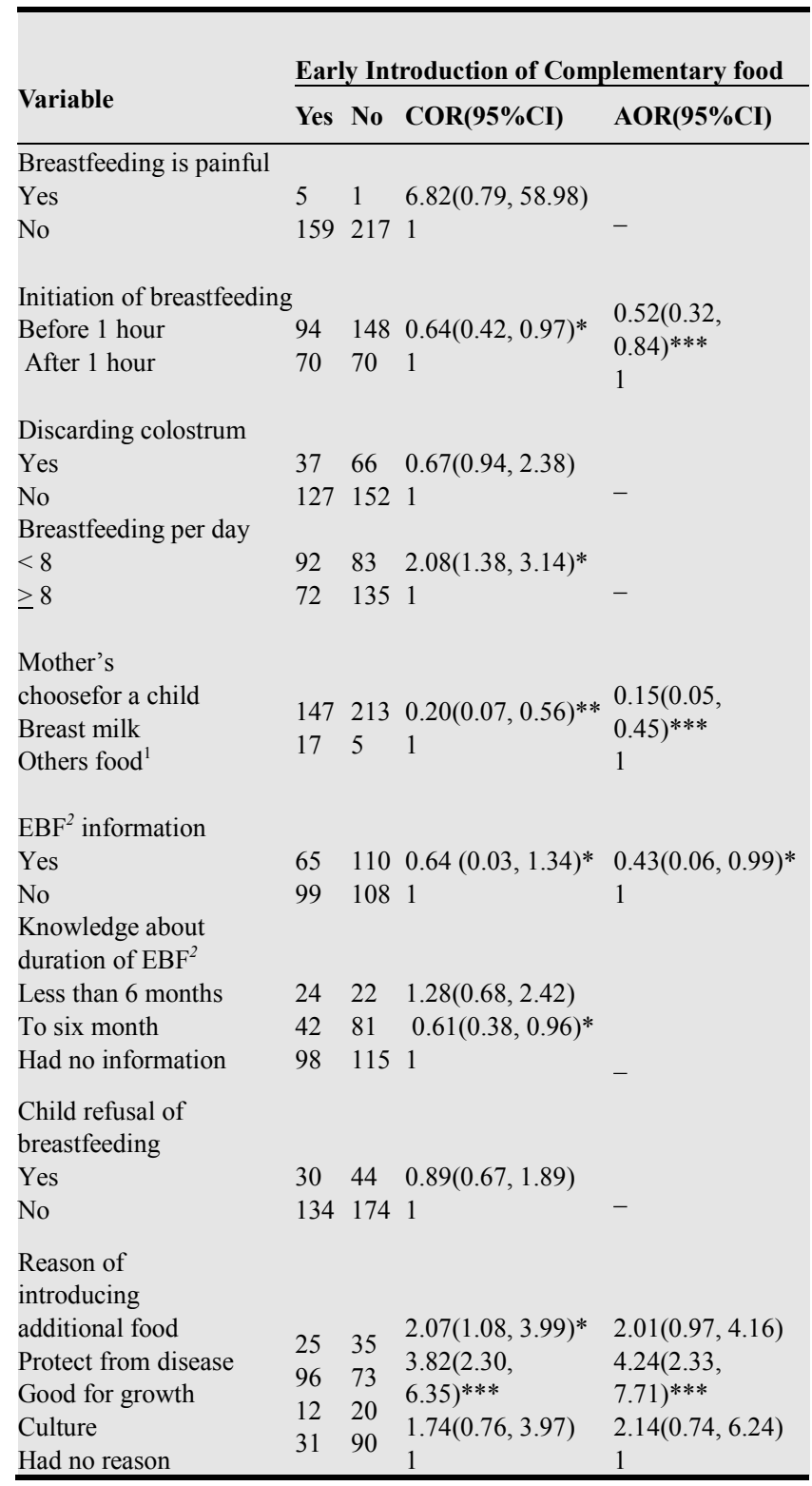

*** Significant at $0.001, * *$ Significant at $0.01 ; *$ Significant at 0.05 .

${ }^{I}$ Others food (cow's milk, fruits, vegetables, any prepared meals).

${ }^{2}$ EBF (Exclusive breastfeeding).

\section{Discussion}

Breastfeeding is considered as a natural gift in Ethiopia. Children were given breast milk as a food. However, according to 2011 Central Statistical Agency report, the prevalence of sub-optimal child feeding is very high [18]. In the rural communities of Ethiopia, $49 \%$ of mothers provided breast milk after one hour of delivery. Nearly $27 \%$ of infants are given prelacteal feeds within the first three days of life $[17,18]$. This study showed that $42.9 \%$ of mothers in JimmaArjoWoreda provided additional food before 6 months. The majority of mothers considered additional food as substances good for normal growth and development of the child. Others introduced additional food as they believed breast milk is not sufficient and used as prevention of disease. Similarly in-depth interview findings showed that breast milk alone may be not sufficient to meet nutritional requirement of infants. This finding is consistent with the findings from Brazil and Indonesia were mothers introduced additional food for they believed that breast milk is not sufficient to meet nutritional need of infants [19, 20].

A large number of mothers, $46.29 \%$ and $53 \%$ in this study provided cow's milk and yogurt before 6 months respectively. In-depth interview with mothers also showed that some mothers provided butter, tena-addam (rue) and fenugreek as preventive medicine against stomachache and other disease. Findings from Zambia and Indonesia also showed that a large proportion of mothers provided formula feeding and cow's milk since they perceived that infant formula and cow's milk had highly valuable nutrients $[20$, 21].

Early introduction of complementary food before 6 months significantly associated with infants' age. As infants' age increased probability of providing additional food increased. Mothers who had below 1 month infants were less early introduced complementary food compared to mothers who had 5-6 months. Similarly, mothers who had 1-2 months infants less likely gave additional food compared to who had 5-6 months. Similar findings were obtained at national level were the age of infants significantly associated with optimal child feeding practices. This finding is also consistent with results from Nigeria were the probability of introducing complementary food increased with age of infants $[2,22]$.

Field activities like keeping livestock was contributing factors to early introduction of complementary food. Mothers who gave some of their time to keep livestock early introduced complementary food before 6 months. This might be due to lack of time to breastfeed appropriately. Indepth interview with mothers also showed that field activity is the major constraints of optimal infant feeding practices.Studies also recommend mothers and families need to be supported for their children to breastfed appropriately [9, 24].

Early introduction of complementary food significantly associated with breastfeeding initiation, mothers' preference for their children, exclusive breastfeeding information and mothers' attitude about breast milk and additional food. This study revealed that breastfeeding initiation had a significant role in the promotion of breastfeeding practices. Mothers who initiated breastfeeding within the first hour of delivery less early initiated complementary feeding compared to who started after one hour of delivery. This might be due to nutritional education given by health extension workers. Studies also showed that lack of knowledge; breastfeeding experiences and pre-lactation feeds are some factors of early introduction of complementary food [23, 24, 25]. 
An exposure to breastfeeding education was negatively associated with early introduction of complementary feeding. Mothers who had information about exclusive breastfeeding to six months less early introduced complementary food. Qualitative findings also showed maternal exposure to breastfeeding education had greater role in the enhancement of optimal child feeding practices. This study is also consistent with the findings from India were maternal knowledge and educational level were determining factors for optimal child feeding practices $[21,26]$.

Maternal perception about breast milk was positively associated with timely initiation of complementary feeding practices. Mothers who considered breast milk as well for normal growth and development of their children were less early provided other forms of food before six months. Studies from Nigeria and Uganda similarly showed the maternal perception about the dietary adequacy of breast milk and social beliefs were some determining factors for early introduction of complementary food [27, 28].

Maternal knowledge and attitude about complementary food were significantly associated with an introduction of complementary food. Mothers who thought that complementary food is good for normal growth of children were more early introduced additional food compared to mothers who had no such perception. Similar findings from Zambia, Gambia and Indonesia showed that maternal knowledge and attitude about optimal child feeding practices had a significant role in the promotion of optimal child feeding practices $[13,21,20]$.

\section{Conclusions}

About $42.9 \%$ of mothersin this study early introduced complementary food before 6 months. Among sociodemographic variables maternal age, child age and keeping livestock significantly associated with early introduction complementary food. In addition optimal child feeding practices like breastfeeding initiation within an hour of child birth, mothers' preference for her child and exclusive breastfeeding informationwere some predictors of appropriate infant feeding practices. Factors associated with early initiation of complementary food should be taken into account while designing intervention strategies and in promotion of strong community based networks using Health Extension Workers and local community resource people as key actors.

\section{References}

[1] UNICEF and WHO. 2003. Global Strategy for Infant and Young Child Feeding, Geneva, Switzerland.

[2] WHO. 2001. Report of the global consultation on Summary of guiding principles forcomplementary feeding of the breastfed child, Geneva Switzerland.

[3] Federal ministry of health. 2005. National strategy for child survival in Ethiopia, Addis Ababa Ethiopia, Family health department publications.

[4] Bernadette Daelmans, Jose Martines, and RandaSaadeh. 2003. Special Issue Base World Health Organization Expert Consultation on Complementary Feeding. Food and Nutrition Bulletin; 24(1): 3-141.

[5] Tefera Belachew.2003. Human Nutrition for Health Science Students Jimma. Public Health Department.

[6] WHO and UNICEF. 20O8. Strengthening action to improve feeding of infants and young children 6-23 months of age in nutrition and child health programmes

[7] WHO and UNICEF. 20O9. Breastfeeding promotion and support in a baby-friendly hospital, Geneva, Switzerland

[8] Food and Nutrition Technical Assistance Project (FANTA). 2006. Working Group on Infant and Young Child Feeding Indicators.

[9] WHO.2010.http://www.who.int/entity/mediacentre/news/ breastfeeding

[10] Daniel J Raiten al. 2007. Maternal nutrition and optimal infant feeding practices. American Journal of Clinical Nutrition; 85(2): 577-583

[11] Gretel H. Pelto, Emily Levitt, and Lucy Thairu. 2003. Improving feeding practices:Current patterns, common constraints, and the design of interventions. Division of Nutritional Sciences; 24(1): 45-57.

[12] Altrena G. Mukuria, Monica T. Kothari and NoureddineAbderrahim. 2006. Infant and Young Child Feeding Update, ORC Macro Calverton, Maryland, USA.

[13] Erik Bohler, IsatouJallowSemega-Janneh, Halvor Holm, Ingrid Matheson and GerdHolmboe-Ottesen. 2001. Promoting breastfeeding in rural Gambia: combining traditional and modern knowledge. Health policy and planning; 16(2):199-205.

[14] R Kruger and GJ Gericke. 2002. A qualitative exploration of rural feeding and weaning practices, knowledge and attitudes on nutrition in South Africa. Public Health Nutrition; 6(2):217-223.

[15] Tonse N. K. RAJU. 2006. Continued barriers for breastfeeding in public and the workplace. The Journal of Pediatrics; 148:677-9.

[16] Federal ministry of health. 2007. Integrated management of new born and child hood illness, Addis, Ababa Ethiopia.

[17] Federal Ministry of Health. 2008. Program Implementation Manual of National Nutrition Program (NNP). Addis Ababa, Ethiopia.

[18] Central Statistical Authority and ORC Macro. 2012. Ethiopia Demographic and Health Survey 2011. Addis Ababa, Ethiopia and Calverton, Maryland.

[19] Jane A Scott et al. 2009. Predictors of the early introduction of solid foods in infants: results of a cohort study. BMC Pediatrics, 9:60.

[20] Inayati et al. 2012. Infant feeding practices among mildly wasted children: a retrospective study on Nias Island, Indonesia. International Breastfeeding Journal 7:3.

[21] Eli Fjeld et al. 2008. No sister, the breast alone is not 
enough for my baby' a qualitative assessment of potentials and barriers in the promotion of exclusive breastfeeding in southern Zambia. International Breastfeeding Journal, 3:26.

[22] Agho et al.: Determinants of exclusive breastfeeding in Nigeria. BMC Pregnancy and Childbirth 2011 11:2.

[23] Tewodros et.al. 2009. Determinants of exclusive breastfeeding practices in Ethiopia. Ethiop.J.HealthDev.23:1.

[24] Federal Ministry of Health. 2004. National strategy for infant and young child feeding. Addis Ababa, Ethiopia.

[25] Haider et al. 2010. Breastfeeding in infancy: identifying the program-relevant issues in Bangladesh. International Breastfeeding Journal 5:21.

[26] Bhatt Shwetal et al. 2012. Knowledge, attitude and practice of postnatal mothers for early initiation of breast feeding in the obstetric wards of a tertiary care hospital of Vadodara city 3(2):305-309.

[27] Ojo M Agunbiade and Opeyemi V Ogunleye.2012. Constraints to exclusive breastfeeding practice among breastfeeding mothers in Southwest Nigeria: implications for scaling up. International Breastfeeding Journal 7:5.

[28] Ingunn et al. 2007. Low adherence to exclusive breastfeeding in Eastern Uganda: A community-based cross-sectional study comparing dietary recall since birth with 24-hour recall. BMC Pediatrics, 7:10.

[29] Jimma Arjo Woreda Adminstration Office. 2008. JimmaArjo Woreda population and housing census document, East Wollega.

[30] Getu Degu and Fasil Tesema. 2005.Biostatisticsfor Health Science Students. Ethiopia Public Health Training Initiative, University of Gonder. 